\title{
O estado da arte das discussões sobre migrações internacionais e políticas públicas
}

\author{
Frederico de Morais Andrade Coutinho
}

Universidade de Brasília (UnB)

Danilo Bijos

Universidade de Brasilia (UnB)

Henrique Marques Ribeiro

Universidade de Brasília (UnB)

$\mathrm{O}$ artigo tem como objetivo apresentar o estado da arte da literatura a respeito de migrações internacionais e sua relação com políticas públicas. Para tanto, selecionaramse artigos publicados nos últimos onze anos (2006 a 2016) nos principais periódicos nacionais segundo classificação Qualis da CAPES. Verificou-se predominância da discussão sobre políticas de integração em comparação ao controle migratório, demonstrando uma maior preocupação dos pesquisadores com as políticas de fixação e atenção às pessoas que migraram em detrimento dos mecanismos de entrada e saída. Identificaram-se majoritariamente estudos relativos às etapas de implementação e avaliação em comparação às etapas de formulação e agenda no âmbito do ciclo de políticas públicas. Observou-se ainda uma fragmentação muito grande dos estudos, com poucos autores tendo publicado mais de uma pesquisa nesse período. $O$ volume de artigos encontrados também é baixo, com uma média de apenas 3,5 artigos por ano. Ante esses resultados, delineou-se uma agenda de pesquisa para futuras investigações.

Palavras-chave: migração, políticas públicas, bibliometria

[Artigo recebido em 22 de março de 2017. Aprovado em 4 de julho de 2017.] 


\section{El estado del arte de las discusiones sobre migraciones internacionales y políticas públicas}

El artículo tiene como objetivo presentar el estado del arte de la literatura acerca de migraciones internacionales y su relación con políticas públicas. Para ello, se seleccionaron artículos publicados en los últimos once años (2006 a 2016) en los principales periódicos nacionales según clasificación Qualis de CAPES. Se verificó predominio de la discusión sobre políticas de integración en comparación al control migratorio, demostrando una mayor preocupación de los investigadores con las políticas de fijación y atención a las personas que migraron en detrimento de los mecanismos de entrada y salida. Se identificaron mayoritariamente estudios relativos a las etapas de implementación y evaluación en comparación a las etapas de formulación y agenda en el ámbito del ciclo de políticas públicas. Se observó una fragmentación muy grande de los estudios, con pocos autores habiendo publicado más de una investigación en ese período. El volumen de artículos encontrados también es bajo, con un promedio de apenas 3,5 artículos por año. Ante estos resultados, se delineó una agenda de investigación para futuras investigaciones.

Palabras-clave: migración, políticas públicas, bibliometría

\section{The state of the art of discussions on international migration and public policy}

This article presents the state of the art of the literature regarding international migrations and its relationship with public policies. Articles published in the last eleven years (2006 to 2016) were selected in the main national journals according to CAPES Qualis classification. The discussion on integration policies was predominant in comparison to migration control, demonstrating a greater concern of the researchers with the policies of fixation and care in spite of to the mechanisms of entry and exit. The majority of the studies were related to the stages of implementation and evaluation of policies in comparison to the stages of formulation and agenda within the scope of the public policy cycle. There was also a large fragmentation in the field, with few authors having published more than one research in the period. The volume of articles found is also low, with an average of only 3.5 articles per year. Faced with these results, a research agenda is outlined for future investigations.

Keywords: migration, public policies, bibliometrics 


\section{Introdução}

De acordo com estimativas do relatório Population Facts, da Organização das Nações Unidas (UNITEd NATIONS, 2015), existem hoje mais de 244 milhões de pessoas construindo suas vidas fora dos seus países de origem. Esse volume total de migrantes internacionais representa um aumento de mais de $40 \% \mathrm{em}$ comparação aos anos 2000. Atualmente, a população migrante corresponde a $3,3 \%$ da população global.

O Relatório Mundial sobre Migrações (INTERnATIOnAL ORgANIZATION FOR MigRATION, 2015) identifica a necessidade dos Estados em prevenir violações de direitos dos migrantes e promover seu bem-estar. Também destaca a questão da integração dos migrantes nas áreas urbanas e a consequente diversidade levada ao âmbito local como fator indutor de desafios e oportunidades. A prestação de serviços públicos a uma população cada vez mais diversificada e com distintas necessidades é um exemplo de desafio, enquanto o fortalecimento das relações entre origem e destino e o aumento da base de mão de obra em idade produtiva são exemplos de oportunidades.

Besharov, Lopez e Siegel (2013, p. 656) apresentam alguns destaques sobre as discussões atuais no campo das migrações. Os autores informam sobre alguns padrões principais que caracterizam os atuais fluxos migratórios. Em relação às motivações, a migração destinada aos países desenvolvidos tem como fator principal o incremento dos ganhos econômicos, sendo que aproximadamente $70 \%$ do fluxo se refere ao migrante econômico. A migração sul-sul também tem a motivação econômica como fator relevante, mas em menor escala, apenas $30 \%$ do fluxo total. Em relação à territorialidade, a migração intrarregional corresponde a $50 \%$ dos fluxos migratórios, sendo que os migrantes geralmente cruzam apenas uma fronteira, deslocando-se para um país vizinho ao seu de origem. Em relação às políticas de atração de migrantes, duas vertentes são bem distintas: 1) o recrutamento de trabalhadores com baixa qualificação para suprir demandas por trabalhos domésticos e manuais; e 2) as políticas de atração de mão de obra altamente qualificada por meio de concessão de vistos especiais.

No Brasil, analisando-se os dados oficiais representados no Gráfico 1, verificase a manutenção de aproximadamente 650 mil migrantes residentes ao longo do tempo, com uma elevação nos últimos anos da série, chegando-se a mais de 810 mil pessoas em 2014. Considerando a população total do país, trata-se de contingente ainda proporcionalmente pequeno, representando $0,4 \%$ da população. 


\section{Gráfico 1 - População estrangeira residente no Brasil (por mil pessoas)}

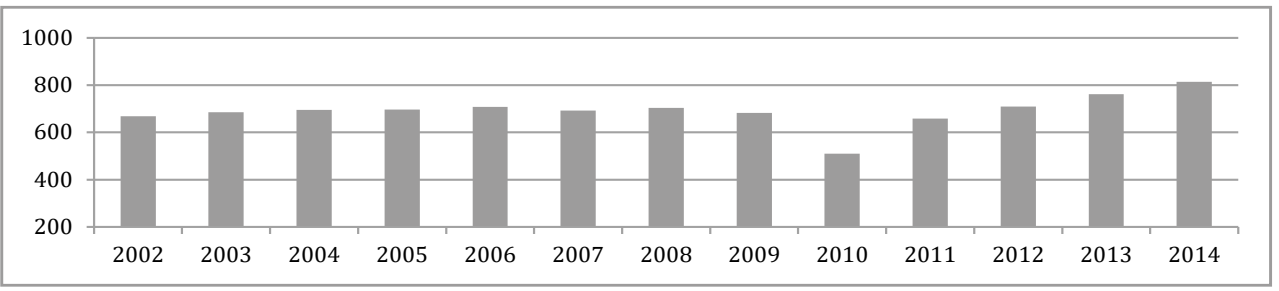

Fonte: Elaboração própria a partir dos Relatórios da PNAD 2002-2014 e do Censo 2010 do IBGE. Nota: Ainda não estão disponíveis os dados de 2015.

Nesse cenário de aumento de fluxos migratórios internacionais e, consequentemente, da intensificação dos desafios e oportunidades vivenciados pelos policy-makers que se propõem a enfrentar essa questão, é necessário conhecer o estágio atual das discussões que relacionam o fenômeno migratório com a estrutura da administração e a prestação de políticas públicas. Para tanto, este artigo pretende colaborar realizando um estudo exploratório de cunho bibliométrico para verificar a produção científica a respeito do tema nos últimos onze anos, entre 2006 e 2016, em periódicos nacionais distribuídos pela classificação Qualis da Coordenação de Aperfeiçoamento de Pessoal de Nível Superior (CAPES) entre A1 e B2 para a área de Administração. Para atingir esse objetivo, a próxima seção apresenta uma breve revisão sobre o fenômeno migratório e sua relação com as políticas públicas no plano internacional. Na sequência, explana-se o método utilizado no levantamento bibliométrico. Adiante, expõem-se os resultados encontrados, com destaque para o estado da arte a respeito do tema, e, por fim, propõe-se uma agenda para pesquisas futuras.

\section{Migrações internacionais e políticas públicas: perspectivas recentes de análise}

Indiscutivelmente, o escopo deste trabalho está relacionado a um conjunto de discussões que envolvem a sobreposição de duas áreas tipicamente multidisciplinares: o campo de estudos das migrações internacionais e o campo das políticas públicas. A temática das migrações internacionais pode receber diferentes tipos de tratamentos ou abordagens, desde a demografia até o meio ambiente. Por sua vez, a mera definição de políticas públicas recebe contribuições das mais diversas áreas do conhecimento.

Assim sendo, as análises sobre migrações internacionais e políticas públicas apresentam inúmeras possibilidades de enfoque. Todavia, no plano internacional, é possível identificar alguns temas recorrentes, tais como: a) políticas de controle 
de entrada; b) políticas de atração de pessoas altamente qualificadas; c) políticas de integração e assistência em países de destino; e d) a relação entre migração, conflito e mudanças climáticas.

A maioria dos países desenvolvidos que se tornam destino de movimentos migratórios internacionais possui políticas de controle que buscam restringir e limitar a migração de refugiados, solicitantes de asilo e pessoas com baixa qualificação. Em sentido oposto, existem políticas bem definidas e de incentivo à recepção de pessoas altamente qualificadas, são as chamadas políticas de brain drain (Besharov; Lopez; Siegel, 2013; Cerna; Chou, 2014; Faggian; Corcoran; ROWE, 2016; WRIGHT, 2014).

Além das regras de controle em âmbito nacional, a literatura internacional discute o papel e os efeitos da instituição, por entes de nível subnacional, de normas atinentes a integração, fiscalização e eventual punição aos imigrantes (CREEK; YODER, 2012; LeWIS et al., 2013; MONOGAN, 2013; TURNER; SHARRY, 2012). Em perspectiva diametralmente oposta se localiza a discussão do transbordamento de regras de blocos internacionais para os países vizinhos, fenômeno denominado de governança externa migratória, atualmente uma realidade para os países limítrofes à União Europeia (WUNDERLICH, 2012).

As políticas de integração, educação e saúde são entendidas como necessárias para que os migrantes se adaptem e iniciem a construção de seu espaço próprio na nova localidade de destino. Alguns governos possuem políticas de integração formalizadas, enquanto em outros elas são relegadas à disposição da sociedade civil e da iniciativa privada em provê-las. Nesse tema, discutem-se as barreiras de acesso e os efeitos dessas políticas de suporte às populações migrantes e também suas implicações para os nacionais desses países (CONDON; FILINDRA; WICHOWSKY, 2015; FosSATI, 2011; KISLEV, 2016; LIEBERT; AMERINGER, 2013).

Outro fenômeno que tem sido bastante estudado em nível internacional se refere à assunção por parte dos migrantes das tarefas de cuidado e atenção a idosos e crianças. Tal discussão envolve as políticas de assistência social, saúde e trabalho. Ainda que haja diferenças entre os países, as principais formas de concretização desses cuidados seriam por meio do trabalho doméstico, trazendo como consequência uma relação de proximidade ao núcleo familiar. Em alguns casos, é possível identificar a prestação desses serviços por agências privadas especializadas ou até mesmo por meio de políticas institucionalizadas que incentivam essas migrações com a facilitação de concessão de vistos (DA ROIT; WEICHT, 2013; DA RoIt; Van Bochove, 2015; Shutes; ChIATTI, 2012; SONG, 2015; VAN HoOREN, 2012; WILLIAMS; BRENNAN, 2012). 
A relação entre mudanças climáticas, conflitos e migrações também constitui foco de atenção do campo. Analisam-se as normas internacionais, os papéis organizacionais de organismos multilaterais e as formas de governança nacionais e regionais aplicáveis às migrações induzidas por mudanças ambientais e por conflitos (GEDdeS; JORDAN, 2012; MARTIN, 2012; SELbY; HOFFMANN, 2012; WARNER, 2012).

Todas essas discussões ocorrem no plano internacional, deixando em aberto a questão de como os periódicos brasileiros relacionam o fenômeno das migrações à prestação de políticas públicas, que é a temática que se pretende discutir no presente artigo.

\section{Método}

A pesquisa analisou artigos publicados entre 2006 e 2016 nos periódicos nacionais da área de avaliação de "Administração, Ciências Contábeis e Turismo", classificados entre A1 e B2 pelo Qualis2014 da CAPES, envolvendo seis etapas de desenvolvimento. A primeira etapa consistiu na identificação do escopo da análise do trabalho. Dos 504 periódicos contidos nesses estratos, selecionaram-se 103 que poderiam, a princípio, discutir questões sobre gestão, administração e políticas públicas, a partir da leitura dos títulos dos periódicos. Foram selecionadas 11 revistas classificadas como A2, 35 como B1 e 57 como B2. Não foram identificados periódicos com classificação A1 (Tabela 1, em anexo).

A segunda etapa tratou da prospecção dos artigos. Buscaram-se, nas bases de dados das páginas institucionais de cada periódico, artigos com as expressões 'migração', 'migrações', 'migrante','migration' e 'migrant' em títulos, palavraschave, resumos e corpo do texto. Foram excluídos os resultados flagrantes em que não se identificava relação do objeto do artigo com a administração pública ou políticas públicas, como 'migração de executivos', 'migração interestadual', 'migração rural-urbana', 'migração animal'. Após essa busca, foram identificados 90 artigos que discutem o tema 'migrações' na perspectiva da mobilidade humana entre países.

A terceira etapa consistiu na elaboração de instrumento de tratamento e análise de dados. $O$ instrumento contém categorias de identificação e de análise do artigo, como: ano, autor, instituição de origem, periódico, título, local do estudo, objetivo do artigo, principais resultados, área da política pública relacionada, etapa do ciclo de políticas públicas enfocada, enquadramento do estudo, natureza da pesquisa, recorte temporal, técnica de coleta de dados, procedimentos de análise dos dados, origem dos dados, e tipo de coleta. 
A quarta etapa tratou da classificação dos artigos nas categorias estabelecidas previamente. Nesse momento, excluiram-se 51 artigos da base de estudo, pois, a partir de uma leitura atenta dessas pesquisas, identificou-se que abordam o tema das migrações, mas não sob a ótica de seu relacionamento com as políticas públicas. Para fins de exemplificação, cabe registrar que foram excluídas pesquisas que abordavam: exclusivamente histórias de vida de migrantes; alterações das relações de gênero no âmbito intrafamiliar; estatísticas de crescimento populacional; dados de saúde/doença dessa população sem vinculação a uma discussão sobre política de saúde; entre outros estudos que não abordavam a esfera pública com implicações para a gestão governamental. Restaram então 39 artigos, que constituíram a base final para a sequência da pesquisa.

A quinta etapa consistiu na utilização de estatística descritiva como forma de ilustrar os achados passíveis de observação quantitativa. A sexta e última etapa, e talvez a mais importante, consistiu na análise substantiva dos resultados encontrados nos artigos revisados. O objetivo dessa análise final foi identificar o estado arte a respeito do tema, ou seja, identificar o conhecimento existente nas publicações nacionais, o que se discute sobre migrações internacionais e sua relação com as políticas públicas e com a administração pública. Ao identificar o conhecimento existente, é possível visualizar que pontos são enfatizados no debate acadêmico desse tema, as lacunas teóricas que ainda precisam ser preenchidas e qual é a direção mais próspera para uma agenda de estudos futuros.

\section{Resultados}

Nesta seção serão apresentados os resultados de autoria e coautoria, instituição de origem dos autores, distribuição das pesquisas nos periódicos selecionados, distribuição temporal e geográfica, métodos e temáticas predominantes e o momento do ciclo de políticas públicas enfocado. 


\section{Autoria e coautoria}

Verifica-se que, dos 39 estudos analisados, $48,7 \%$ dos artigos foram produzidos por um único autor, enquanto os $51,3 \%$ restantes foram produzidos em coautoria. Contando autores e coautores, chega-se a um total de 63 pesquisadores envolvidos nessa amostra, sendo que apenas 5 deles se repetem com 2 artigos produzidos ${ }^{1}$, não havendo nenhum pesquisador relacionado a 3 ou mais pesquisas. Esses resultados indicam fragmentação dos estudos e baixa relação entre os autores. As múltiplas possibilidades de investigação que relacionam os temas de migrações internacionais e políticas públicas podem indicar uma pista sobre a baixa relação entre os pesquisadores. Estudos que foquem no tema da educação não necessariamente precisarão buscar fontes que abordem a questão da segurança nas áreas de fronteira, por exemplo. A despeito disso, a fragmentação encontrada pode indicar ausência de visão multidisciplinar na abordagem do fenômeno migratório, e com isso impedir avanços mais significativos no tratamento das mais diversas dificuldades encontradas por essas pessoas.

\section{Instituição de origem}

Analisando as instituições de origem de todos os 63 pesquisadores, identificouse que 24 se vinculam a instituições nacionais e 29 a instituições internacionais, com destaque para universidades e centros de pesquisa de Portugal, com 13 afiliações, e dos Estados Unidos, com 6 afiliações. Não foi possível identificar a instituição de origem de 10 pesquisadores, que responderam por 9 pesquisas da amostra.

Avaliando as instituições de pesquisa em termos de quantidade de estudos produzidos dentro da amostra selecionada, destacam-se: a Universidade de São Paulo (USP) e a Universidade Federal de Minas Gerais (UFMG), com 4 pesquisas cada uma; a Universidade Aberta (Portugal) e a Universidade do Minho (Portugal), com 3 pesquisas cada uma; e a Faculdade de Ciências Médicas da Santa Casa de São Paulo (FCMSCSP) e a Universidade do Porto (Portugal), com 2 estudos cada. Todas as demais instituições aparecem com apenas 1 estudo produzido.

Ante esses números, é possível averiguar um grau relativamente considerável de internacionalização das pesquisas no campo das migrações publicadas em

\footnotetext{
${ }^{1}$ Bäckström publicou dois artigos, nos anos de 2011 e 2012, baseados em pesquisas qualitativas que investigaram a integração de populações migrantes às políticas da área da saúde. Já Patarra publicou dois artigos no ano de 2006, um deles apenas teórico e outro teórico-empírico baseado em uma pesquisa quantitativa. 0 primeiro relacionado à política de assistência social e o segundo à de trabalho. Reis, por sua vez, publicou dois artigos teóricos, em 2006 e 2009, ambos relacionados à área de segurança pública. Já Silveira publicou dois artigos teórico-empíricos, em 2009 e 2013, ambos baseados em pesquisas qualitativas e relacionados à área da saúde. Vilela, por fim, publicou também dois artigos teórico-empíricos, em 2011 e 2015, que se basearam em pesquisas quantitativas e relacionados à área de trabalho.
} 
periódicos brasileiros. Dos pesquisadores em que foi possível identificar a instituição de origem, 54,7\% informaram vinculação a alguma instituição internacional, sendo responsáveis pela autoria ou coautoria de 16 estudos dos 30 artigos que identificaram a origem dos autores.

\section{Periódicos}

Dos 103 periódicos em que se procedeu a busca para este trabalho, os 39 artigos da amostragem final se distribuem em 19 deles, sendo que 6 possuem mais de 1 pesquisa selecionada, merecendo destaque na Tabela 2.

Tabela 2 - Distribuição de artigos por periódicos

\begin{tabular}{lcc}
\hline Periódico & Classificação & Frequência \\
\hline Estudos Avançados & B2 & 8 \\
\hline Saúde e Sociedade (USP) & B2 & 7 \\
\hline Revista Brasileira de Estudos de População & B1 & 4 \\
\hline Cadernos de Saúde Pública (ENSP) & A2 & 3 \\
\hline Educação e Pesquisa (USP) & B2 & 2 \\
\hline Revista Brasileira de Ciências Sociais & B1 & 2 \\
\hline Outros & - & 13 \\
\hline Total & & 39 \\
\hline
\end{tabular}

Fonte: Elaboração própria.

\section{Distribuição temporal}

No período enfocado, 2006 a 2016, verifica-se uma média de publicação de 3,5 artigos por ano. $O$ ano de 2006, com 8 publicações, desvia bastante dessa média em razão de uma edição especial da revista Estudos Avançados, que publicou um dossiê pertinente ao tema das migrações, do qual 7 artigos foram selecionados como pertinentes à amostra desta pesquisa. Excluindo o ano de 2006, verifica-se uma tendência constante de aumento nas publicações, ainda que pequena, destoando apenas o último ano da série, com apenas três artigos publicados (Gráfico 2). 


\section{Gráfico 2 - Distribuição temporal dos artigos da amostra}

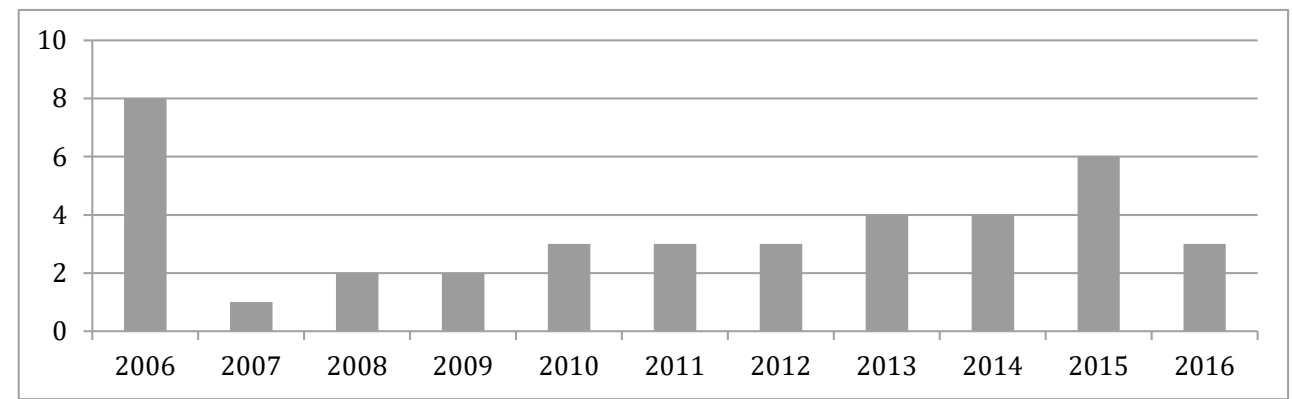

Fonte: Elaboração própria.

\section{Distribuição geográfica}

Acerca da distribuição geográfica das pesquisas, aproximadamente $54 \%$ abordam o fenômeno migratório e sua vinculação direta com o território brasileiro ou com seus nacionais. Desses, 25,6\% abordam o Brasil como destino de fluxos migratórios, $20,5 \%$ como origem, e 7,9\% explicitam fenômenos fronteiriços, em que o Brasil é tanto origem quanto destino.

Entre os $46 \%$ dos estudos que não enfocam o Brasil ou seus nacionais, destacamse as análises do fenômeno em âmbito regional ou global em 15,4\% das pesquisas, sendo que os $30,6 \%$ restantes abordam outras relações bilaterais, conforme se verifica no Gráfico 3.

\section{Gráfico 3 - Distribuição geográfica dos movimentos migratórios}

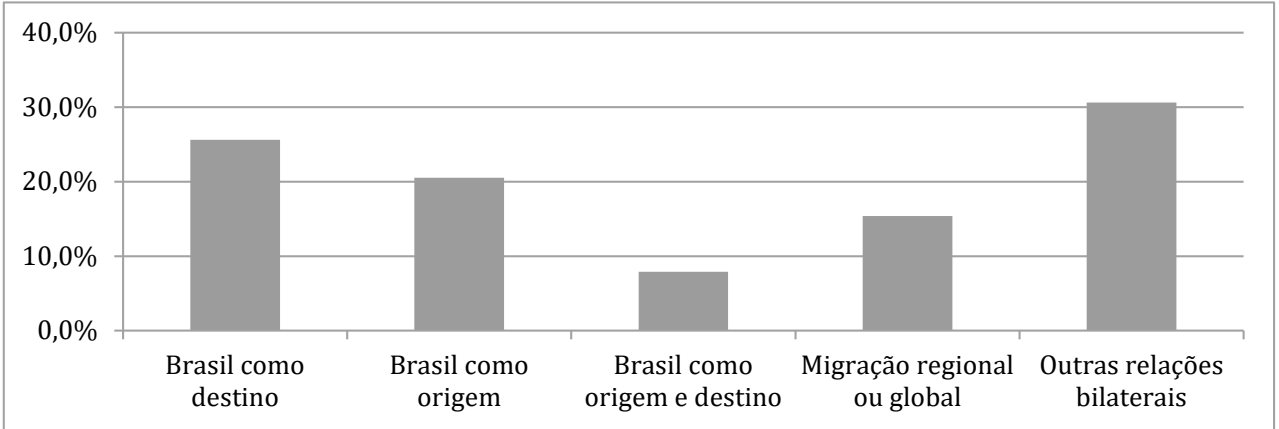

Fonte: Elaboração própria.

\section{Enquadramento do estudo}

Dos 39 artigos da amostra, 23 deles se enquadram como teórico-empíricos, enquanto que os 16 restantes são revisões teóricas. 
Natureza da pesquisa

Trata-se de identificar se os estudos são qualitativos, quantitativos ou multimétodo. Para tanto, selecionaram-se apenas os artigos teórico-empíricos, uma vez que às revisões teóricas não se aplica essa classificação. Verificase predominância dos estudos qualitativos (56,5\%), conforme ilustrado pelos resultados apresentados no Gráfico 4.

\section{Gráfico 4 - Distribuição dos artigos da amostra por natureza da pesquisa}

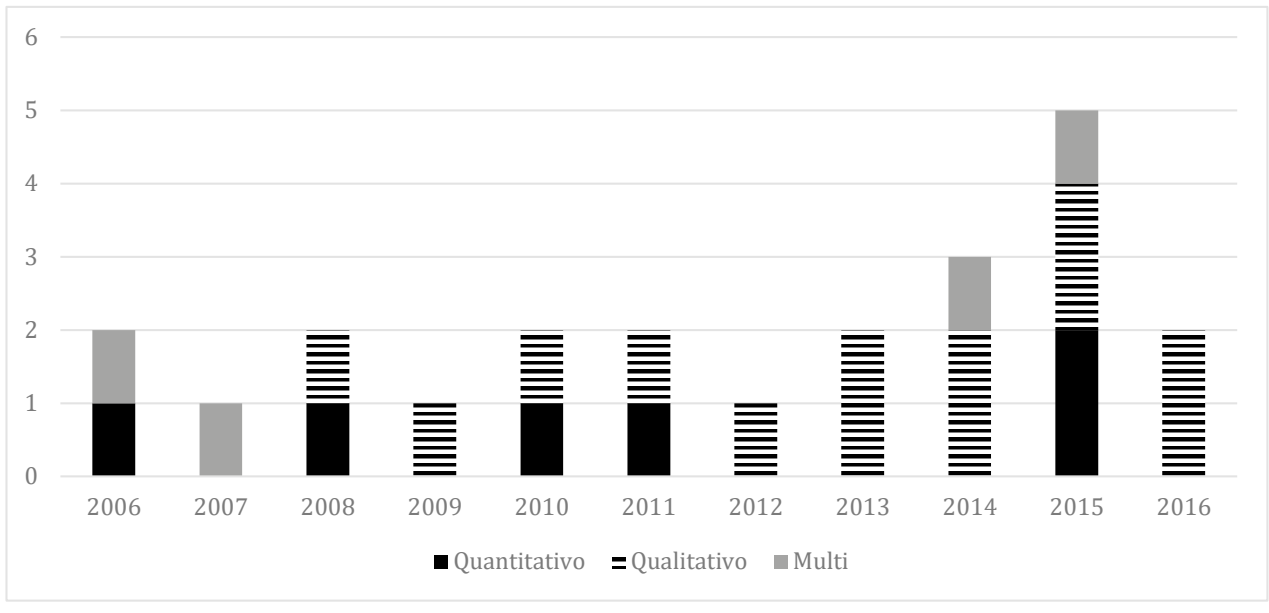

Fonte: Elaboração própria.

\section{Recorte temporal}

Dos 23 estudos teórico-empíricos, 22 fazem um recorte temporal transversal dos dados, ou seja, apresentam um retrato do momento. Apenas 1 artigo apresenta dados de forma longitudinal. Essa tendência pode indicar uma dificuldade em se obter dados em diversos momentos de tempo, seja pela ausência de indicadores oficiais que meçam informações sobre as populações migrantes, seja pelo custo de se acessar respondentes ou entrevistados em mais de um período.

\section{Técnicas de coleta dos dados}

Em relação à coleta dos dados, o destaque é conferido ao procedimento das entrevistas, seguido pelas técnicas documental e de observação. O Gráfico 5 apresenta os resultados encontrados. Nota-se que a soma de todas as técnicas ultrapassa a quantidade total de artigos teórico-empíricos, o que é explicado pelo uso de múltiplos procedimentos em uma mesma pesquisa. Dos 23 artigos analisados, 7 apresentam essa característica, sendo que 3 utilizaram 2 técnicas, e 4 utilizaram 3 ou mais procedimentos. 
Gráfico 5 - Distribuição dos artigos da amostra por técnica de coleta dos dados

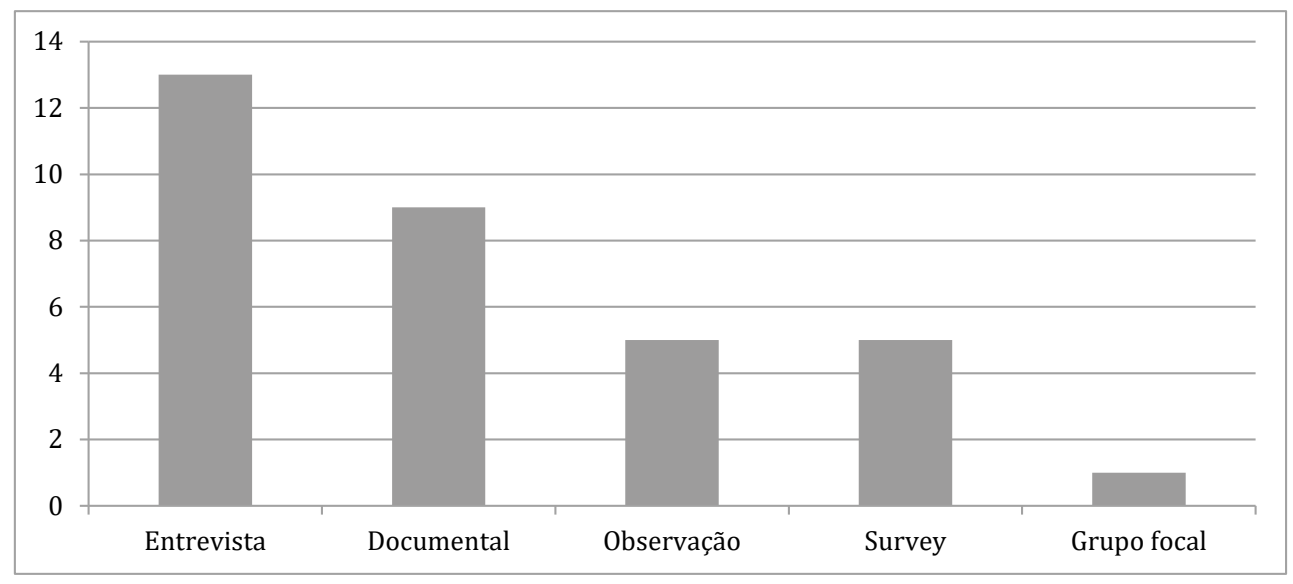

Fonte: Elaboração própria.

Procedimento de análise dos dados

Em relação à análise dos dados, destaca-se a quantidade expressiva de artigos que não informaram que procedimento foi utilizado, quase $35 \%$ dos estudos teóricoempíricos. Todos esses possuem natureza qualitativa. Essa é uma constatação significativa, que pode gerar críticas quanto à validade e confiabilidade dessas pesquisas, cabendo fazer uma ressalva a partir das discussões de Paiva Júnior, Souza Leão e Mello (2011). As pesquisas qualitativas precisam explicitar seus critérios e processos de investigação, de modo a permitir potenciais replicações do estudo, em que pese o reconhecimento da historicidade dos fenômenos e de sua construção social contextual.

Em sentido contrário, destaca-se que 3 pesquisas identificaram 2 tipos de procedimentos de análise, o que justifica que os valores do Gráfico 6 não somem um total de 23 procedimentos, mas sim 26. A estatística descritiva desponta como o método de análise mais utilizado, seguido da análise de conteúdo e da estatística inferencial. 
Gráfico 6 - Distribuição dos artigos da amostra por procedimento de análise dos dados

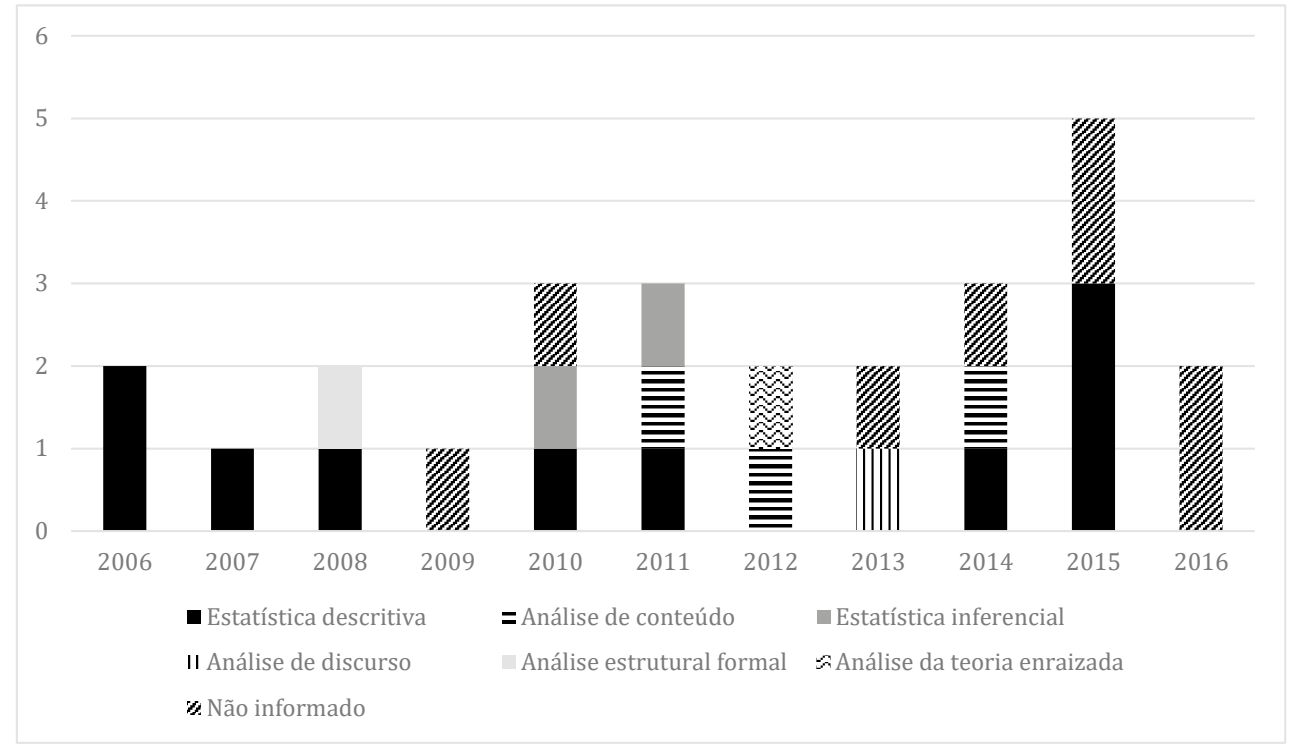

Fonte: Elaboração própria.

Origem dos dados

Conforme apresentado no Gráfico 7, a obtenção de dados de origem primária é majoritária, o que reforça a inferência de que o fenômeno estudado ainda é pouco permeável a bases de dados oficiais. Alguns poucos artigos utilizaram fontes de dados primárias combinadas com secundárias, evidenciando um esforço louvável de diversificação de fontes.

\section{Gráfico 7 - Distribuição dos artigos da amostra por origem dos dados}

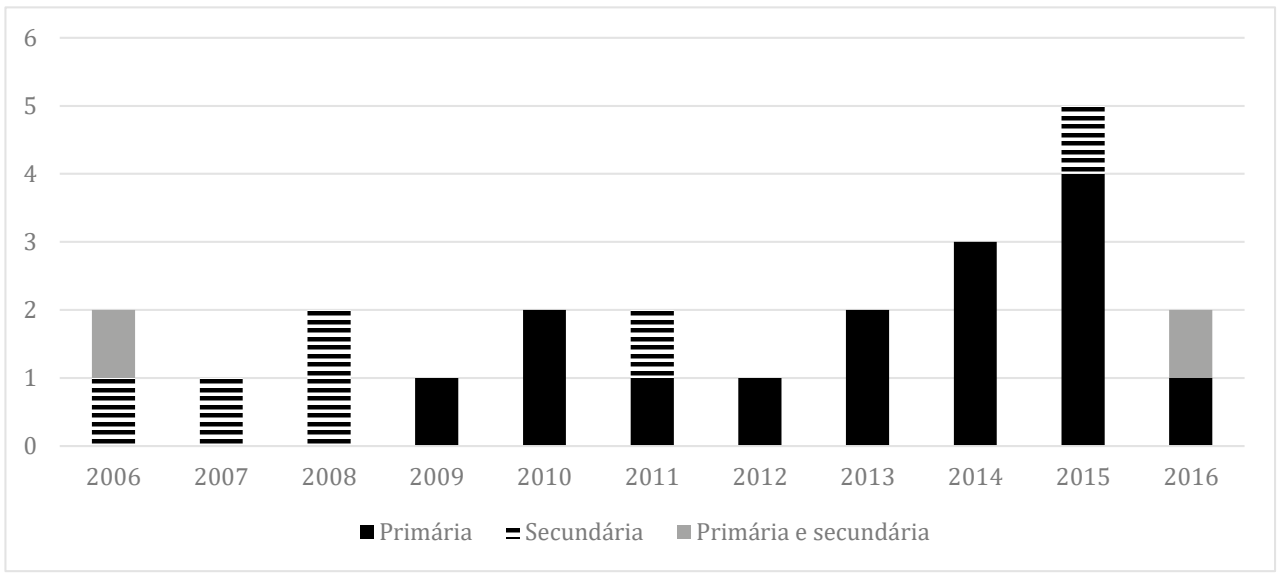

Fonte: Elaboração própria. 


\section{Tipo de Coleta}

A descrição dos resultados acerca do tipo de coleta se restringe aos artigos cujas origens dos dados apresentam a coleta direta, ou seja, primária. Desses 17 artigos, 15 fizeram a coleta presencialmente, 1 à distância, e 1 não informou o procedimento.

\section{Temáticas predominantes}

A seguir, busca-se averiguar como os artigos selecionados se distribuem nos diversos temas de políticas públicas. Uma primeira classificação se refere aos: a) artigos que tratam principalmente de questões referentes ao fluxo, controle migratório e regras de permanência; b) artigos que abordam a questão da integração às políticas públicas que atendem e são direcionadas aos migrantes; c) artigos que discutem ambos os pontos a) e b); e d) artigos que analisam a relação dos migrantes com seus países de origem, abordando políticas como a de remessas, por exemplo. Os resultados são apresentados no Gráfico 8. Relevante notar a predominância de estudos referentes à integração dos migrantes no território nacional, demonstrando a preocupação com as pessoas que já ingressaram no território em detrimento da análise dos fenômenos de controle de fronteiras.

\section{Gráfico 8 - Distribuição dos artigos da amostra por temas}

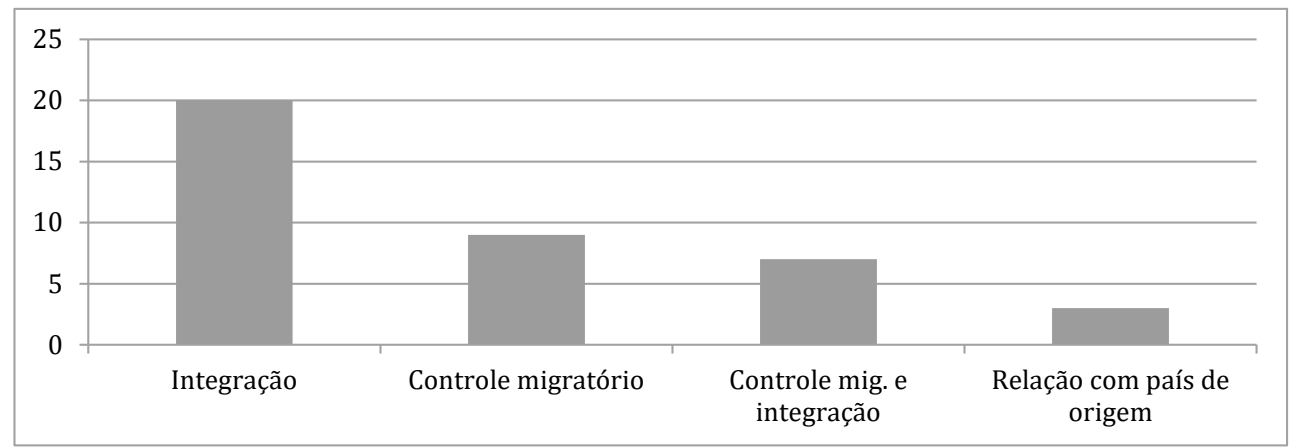

Fonte: Elaboração própria.

Uma outra classificação possível se refere à área principal de política pública a que o estudo se refere. Ressalta-se que algumas pesquisas se alinham a mais de uma área de política pública, sendo avaliado nesse momento a área que prepondera. Verificase que os três maiores resultados estão ligados às políticas de saúde, segurança e trabalho, correspondendo a quase $70 \%$ do total dos artigos selecionados. Os demais artigos se distribuem entre as áreas de educação, assistência e cultura, conforme pode ser visto no Gráfico 9. 
Gráfico 9 - Distribuição dos artigos da amostra por área de política pública

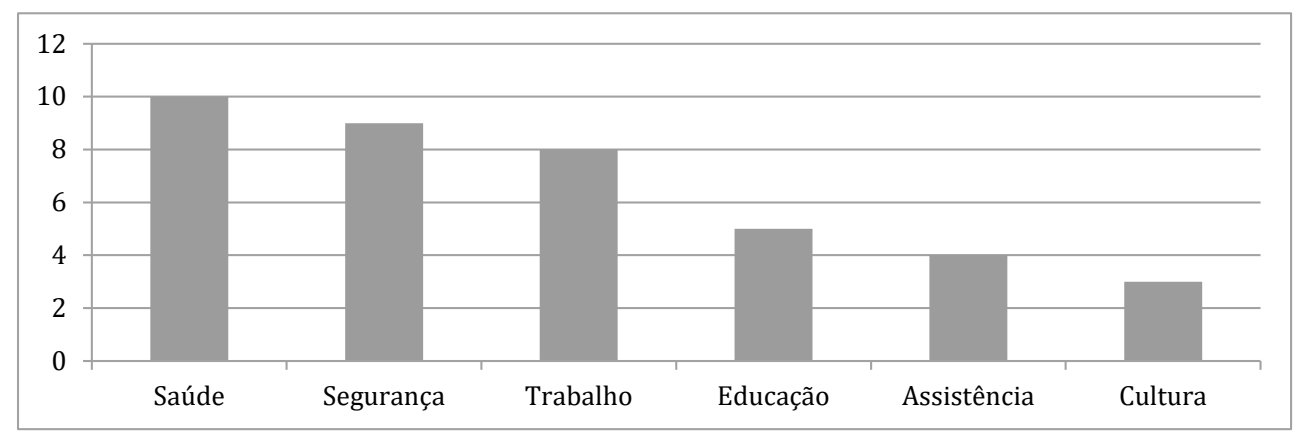

Fonte: Elaboração própria.

Essa distribuição evidencia o quão plural e multifacetado é o fenômeno migratório, permitindo miríades de análises, seja nas perspectivas de controle migratório ou integração no território, seja nos múltiplos campos temáticos das políticas públicas.

\section{Ciclo de políticas públicas}

Além das classificações temática e por área de política pública, buscou-se identificar em qual etapa do ciclo de políticas públicas a discussão migratória se inseria. Consideraram-se as etapas de formulação, agenda, implementação e avaliação. As etapas de formulação e agenda são anteriores ao processo decisório de implementar a política. A etapa de formulação compreende o espaço para o desenho da política pública e de diagnósticos prévios. Já a etapa de agenda se refere ao momento de discussão dos atores relevantes, das condicionantes prévias, dos entraves e potencialidades do tema entrar no rol formal das políticas públicas. A etapa de implementação faz referência ao momento de execução da política, nela os estudos apresentam algum déficit de implementação, alguma oportunidade de melhoria ou correção de rumos. Já a última etapa, como o próprio nome indica, apresenta avaliações da política pública, sejam embasadas em percepções individuais, sejam fundamentadas em abordagens de nível meso ou organizacional.

Por certo, a divisão estanque dos artigos em fases do ciclo não poderia ser concretizada, dada a dinamicidade do processo de policy making e também das pesquisas, que muitas vezes perpassam mais de uma fase do ciclo. Apesar dessas ressalvas, é possível retirar alguns insights dessa classificação aproximada apresentada na Gráfico 10. 


\section{Gráfico 10 - Distribuição dos artigos da amostra por etapa do ciclo de política pública}

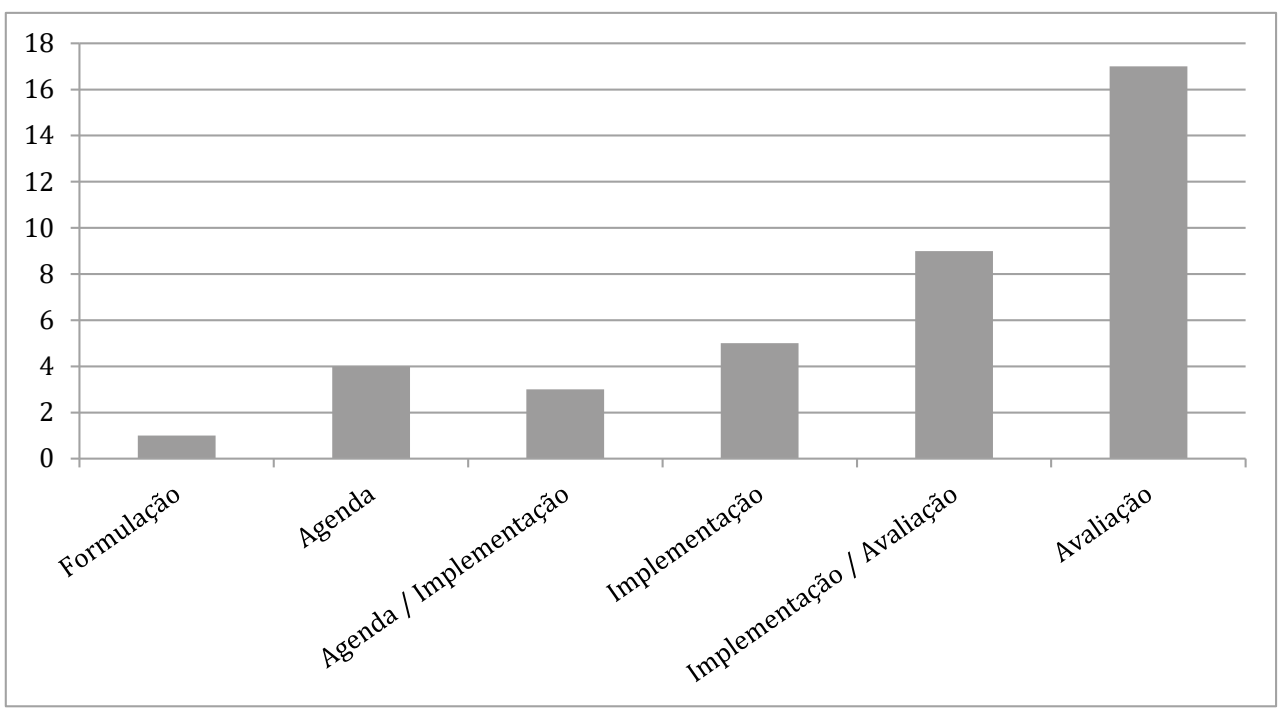

Fonte: Elaboração própria.

Apenas 1 estudo trata do momento de formulação da política pública, representando algo como que $2 \%$ da amostra. Sobre a etapa de agenda, 7 pesquisas a abordam, algo perto de $18 \%$ dos estudos (10\% exclusivamente essa etapa). Referente ao momento de implementação, 17 artigos são identificados, representando $44 \%$ da amostra (13\% exclusivamente essa etapa). 0 momento de avaliação é discutido em 26 pesquisas, sendo $67 \%$ do total (43\% exclusivamente essa etapa). A soma ultrapassa $100 \%$ em virtude de vários artigos abordarem mais de uma etapa do ciclo de políticas públicas.

Esses números nos permitem verificar que os estudos sobre implementação e avaliação, no âmbito da amostra deste artigo, são preponderantes em relação aos estudos de formulação e agenda da política migratória, sugerindo que essa etapa pré-decisória e anterior à implementação das políticas pode ser mais explorada.

\section{Estado da arte e agenda de pesquisa}

A partir da análise dos 39 artigos, é possível delinear as discussões recentes mais proeminentes nos periódicos de referência nacionais, em que pese a multiplicidade de enfoques dentro de cada política temática em sua articulação com o fenômeno das migrações internacionais. Os temas de saúde das mulheres migrantes, regulação da entrada e segurança, seletividade das autorizações e precariedade das condições no campo do trabalho, interculturalidade da educação, remessas financeiras e alívio da pobreza, e a fragilidade na articulação de políticas 
em zonas de fronteira são recorrentes. As principais discussões serão elencadas na sequência, permitindo uma visualização mais qualificada e ao mesmo tempo global do que o campo está produzindo.

A discussão que se estabelece no plano da política de saúde apresenta um claro recorte de gênero. Cerca de $40 \%$ dos estudos enfocam a saúde da mulher migrante. Tais estudos analisam a proposição de um serviço diferenciado de atendimento (AlMEIdA et al., 2014), comparam o uso dos serviços no país de origem e no país de destino (MADI; CASSANTI; SILVEIRA, 2009), ou investigam as dificuldades de acesso aos serviços (DeEb-SosSA et al., 2013; Topa; NeVES; NogueIRA, 2013).

Também evidenciando as dificuldades de acesso aos serviços de saúde, mas sem o recorte de gênero, Goldberg e Silveira (2013) informam que a condição de clandestinidade, isto é, a irregularidade administrativa e migratória, gera estigmatização no atendimento realizado pelos serviços de atenção locais. Outra discussão que se apresenta nesse campo de política pública faz referência à relação entre status migratório, nível socioeconômico e o acesso à saúde. Para Bäckström (2011) e Alves e Bäckström (2012), o nível socioeconômico é mais determinante do que as diferenças de cultura e etnicidade nas práticas de saúde das populações migrantes. Em relação ao momento do ciclo das políticas públicas enfocado nos artigos que discutem o tema da saúde, verifica-se majoritariamente discussões atinentes às etapas de implementação e avaliação. Como visto, discutem-se déficits de execução da política e apresentam-se avaliações sobre o acesso à saúde pela população migrante.

No plano da segurança, a relação com a migração se estabelece majoritariamente em conexão com a regulamentação da entrada, discussões essas que enfocam menos o território brasileiro e mais análises focadas em países desenvolvidos que recebem grandes contingentes de migrantes. Reis (2006), Brancante e Reis (2009), e Brito (2013) delineiam essa tendência, em que a agenda de segurança gera políticas de restrição para brecar a emigração de países menos desenvolvidos e até mesmo para reduzir os direitos daqueles que já se encontram no território de destino. Discussão ainda minoritária é a análise dos casos de violência contra migrantes, que, no território brasileiro, pode ser vista a partir do estudo de Leão e Demant (2016). Nesse âmbito, a garantia de canais institucionalizados para exercer suas reivindicações, e, no limite, a conquista de seus direitos políticos podem ser fatores preponderantes a reduzir as violações sofridas por essas populações. No tema da segurança, o conjunto dos artigos apresenta maior pluralidade na abordagem das etapas do ciclo das políticas públicas. Observam-se estudos sobre formulação, agenda, implementação e avaliação. Discute-se a formulação de regras para a proteção de migrantes, o papel da mobilização política como fator de alteração da 
agenda da segurança, verificam-se déficits na implementação da política gerando um Estado violador, e avaliam-se os impactos da securitização da imigração.

Em relação à política de trabalho, destaca-se a sua vinculação ao tema do controle migratório. Segundo Vilela e Sampaio (2015), ao analisar as autorizações de permanência a estrangeiros no Brasil entre 2005 a 2011, infere-se certa seletividade e restritividade, dada a predominância de autorizações a trabalhadores profissionais e investidores, homens, altamente qualificados e de países, em geral, mais desenvolvidos (norte-americanos, europeus e asiáticos). De maneira alinhada, mas analisando fenômeno inverso, acerca da entrada de indocumentados, Araujo, Filartigas e Carvalho (2015) descrevem as difíceis condições de trabalho de imigrantes bolivianos no Brasil. Em outro artigo, Vilela (2011) chega a resultados que indicariam uma discriminação positiva dos imigrantes que trabalham no Brasil. À primeira vista, esse resultado poderia ser visto com estranheza, mas justifica-se por a base de análise se restringir aos imigrantes documentados regularmente, que, em sua maioria, são bem qualificados. No âmbito da política do trabalho, os estudos sobre implementação predominam, discutindo a precariedade das condições das pessoas que migram irregularmente. No entanto, estudos sobre agenda e avaliação também podem ser encontrados, como a discussão sobre integração legislativa e a constatação da seletividade da política.

Sobre a política pública de educação, não se verificou na amostra estudos sobre a integração do migrante no sistema brasileiro de ensino, o que se traduz em um convite para pesquisas futuras. Identificaram-se estudos que abordam a questão no âmbito de países como Espanha, Portugal, Estados Unidos, República Dominicana e Equador, relatados nos periódicos nacionais. Nessa amostra, Del-Sol-Flórez (2012) destaca a dificuldade em se estabelecer modelos de educação pluricultural e pluriétnica. $\mathrm{O}$ autor ressalta a falta de orientações, de recursos competenciais e de currículos de raiz intercultural. Já Bartlett, Rodriguez e Oliveira (2015) enfatizam o espaço da escola como indutor da cidadania e da inclusão, ao mesmo tempo em que expõe os migrantes ao poder do Estado, moldando suas identidades. No âmbito nacional, a discussão travada pode ser ilustrada pelo trabalho de Ramos e Velho (2011), em que abordam a propensão de doutorandos brasileiros migrarem. Esses autores identificam que essa propensão é comparativamente baixa em relação ao cenário internacional e afirmam que a política estatal de formação de doutores no Brasil vem reforçar essa tendência. No campo da educação, a maioria dos estudos se aproxima das discussões avaliativas, enfatizando a não existência de um padrão de educação intercultural e pluriétnica.

O debate sobre remessas internacionais de migrantes a seus familiares no país de origem localiza esse âmbito da política migratória como política assistencial. No 
Brasil, Martes e Soares (2006) verificam que os efeitos produtivos dessas remessas são muito baixos, de modo que seria irreal esperar que atenuassem a pobreza e promovessem o desenvolvimento. Os autores informam que, do montante de remessas, algo entre 1 e 4 bilhões de dólares para o ano de 2000 (considerando a população máxima e mínima de emigrantes internacionais estimados), cerca de $76 \%$ se destinam à ajuda familiar, ou seja, não são utilizadas com propósito produtivo, mas sim com despesas correntes do dia a dia. Brzozowski (2012) discorda em termos, uma vez que informa que os efeitos não são sentidos no cenário macroeconômico, mas o são em nível meso, regional. Patarra (2006) alarga esse debate evidenciando o outro lado da balança, qual seja, o investimento que fora feito pelos países de origem nesses cidadãos antes de migrarem e sua contribuição produtiva no país de destino. A despeito de um eventual efeito positivo das remessas internacionais aos países de origem, há que se considerar que esses cidadãos receberam investimentos de seus próprios países, como na sua educação e saúde, e que agora são utilizados em benefício dos países de destino.

Uma questão que também aparece de forma recorrente na amostra analisada é o estudo das zonas de fronteira brasileiras e como a política migratória nacional não apresenta soluções para os deslocamentos humanos nessas localidades. Essa discussão articula de forma transversal os mais diversos campos das políticas públicas, como saúde, trabalho e segurança. Véran, Noal e Fainstat (2014) e Santos (2016) abordam aspectos do fluxo haitiano, que gerou uma crise na prestação de serviços no Estado do Amazonas, dada a ausência de articulação e direcionamento das políticas migratórias. Falhas na assistência e na proteção evidenciam que a gestão interfederativa das questões migratórias não foi eficiente.

Para além das crises geradas por movimentos migratórios não facilmente previsíveis, o próprio fluxo ordinário e histórico de fronteiriços da Bolívia, Peru, Colômbia, Venezuela e Guiana, para citar alguns, também gera problemas nas zonas de fronteira. Os entraves burocráticos e jurídicos para trânsito e permanência dessas pessoas acabam por agravar violações de direitos humanos (OLIVEIRA, 2006). Essas áreas se tornam corredores para o narcotráfico, contrabando e outros crimes. Falta uma política específica que possa dar conta dessas configurações socioculturais de fronteira que permita a garantia de um mínimo de cidadania para essas pessoas (RODRIGUES, 2006).

Em que pese a multiplicidade de discussões que foram encontradas na base de artigos desta pesquisa, algumas questões não foram identificadas ou foram pouco exploradas nos periódicos nacionais, podendo constituir uma agenda de pesquisas futura. A relação entre meio ambiente e migrações, seja no âmbito das políticas, seja no âmbito dos impactos, não foi observada. A integração de migrantes no 
sistema educacional brasileiro é outra lacuna. A existência ou não de uma política do Estado brasileiro com suas populações diaspóricas também não é enfocada.

Tema menos recorrente, mas que poderia ser endereçado com mais ênfase pelos pesquisadores, é a regularização de migrantes indocumentados. As disputas internas à administração para se adaptar à realidade fática da presença dos migrantes e recebê-los em seu território ou recorrer a instrumentos jurídicos de expulsão e deportação é um dilema para os agentes públicos.

Os mecanismos de governança entre os órgãos da administração pública que têm interface com os migrantes não são enfocados em nenhum artigo. Considerando o migrante como um cidadão que tem necessidades nos mais diversos campos das políticas públicas, faz-se necessário compreender essas dinâmicas, em face de contradições na prestação das políticas.

A formulação de políticas e a construção das agendas nacionais referentes ao tema da migração também carece de uma análise mais detida. Conforme visto na seção de resultados, há predominância dos estudos sobre as etapas de implementação e avaliação das políticas. Faz-se necessário compreender, por exemplo, quais seriam os fatores a impulsionar a adoção de políticas públicas mais liberais ou conservadoras pela administração.

Para além dessas discussões, o campo carece de estudos sobre as relações entre os países de origem e destino, os vínculos mantidos pelas populações diaspóricas, e o impacto da migração nos países de origem. Seria a migração um fator de perpetuação das desigualdades entre países emissores e receptores? No âmbito da administração pública, é importante estudar as políticas públicas na origem, que podem estancar a migração, ou até mesmo promover relações mais saudáveis com suas populações que emigraram.

\section{Considerações finais}

O presente estudo apresentou o estado da arte a respeito das múltiplas relações entre as políticas públicas e os movimentos migratórios internacionais por meio de uma investigação bibliométrica nos principais periódicos nacionais do campo da Administração. Na análise procedida, verificou-se predominância da discussão sobre políticas de integração em relação ao controle migratório, demonstrando uma maior preocupação dos pesquisadores com as políticas de fixação e atenção às pessoas que migraram em detrimento dos mecanismos de entrada e saída. Dentre as políticas temáticas, saúde, segurança e trabalho se destacam, compondo as discussões de mais de $70 \%$ da amostra. 
Uma constatação que abre espaço para futuros estudos é a discussão das etapas de formulação e agenda em comparação às discussões sobre implementação e avaliação de políticas públicas. Entende-se que investigações sobre o momento prédecisório em políticas públicas, com a identificação dos determinantes da adoção de uma determinada linha de política, são tão importantes quanto os estudos sobre a implementação da política escolhida e sua avaliação. Mecanismos de governança, processos de regularização de migrantes e relações com as populações diaspóricas também são pouco enfatizados pela literatura.

Por meio da revisão, observou-se uma fragmentação muito grande dos estudos, com poucos autores tendo mais de uma pesquisa publicada. O volume de artigos também é baixo; considerando-se o período de 11 anos de análise, verificou-se uma média de apenas 3,5 artigos por ano. Conclui-se que falta robustez e uma visão mais transversal e integrada da relação entre o fenômeno migratório e as políticas públicas nos periódicos nacionais.

Importante mencionar as limitações da pesquisa em relação à definição dos periódicos analisados e em relação à classificação dos artigos. A pesquisa utilizou como recorte apenas as revistas classificadas nos estratos superiores de acordo com o Qualis da CAPES para a área de avaliação "Administração, Ciências Contábeis e Turismo". Caso o critério para a seleção das revistas tivesse sido outro, eventualmente abrangendo periódicos de outras áreas de avaliação das Ciências Sociais, os resultados se alterariam. De modo que o estudo atual não deve ser tratado de forma estanque e definitiva, mas apenas como uma contribuição de pesquisa. Em relação à forma de classificação dos artigos selecionados, procedeu-se a uma análise manual que carrega em si a subjetividade dos pesquisadores, de modo que uma replicação exata do procedimento metodológico por outros pesquisadores poderia implicar resultados distintos. A despeito das limitações apresentadas, tentou-se tornar claro o procedimento de busca, análise e resultados, visando assim aumentar a validade e confiabilidade da pesquisa.

\section{Referências bibliográficas}

ALMEIDA, Ligia Moreira et al. Assessing maternal health care inequities among migrants: a qualitative study. Cadernos de Saúde Pública, v. 30, n. 2, p. 333-340, 2014. ALVES, Fátima; BÄCKSTRÖM, Bárbara. Lidar com a doença mental - a pluralidade de sistemas de cuidados e de itinerários terapêuticos: análise comparativa de dois estudos efectuados junto de duas populações residentes em Portugal. Saúde e Sociedade, v. 21, n. 3, p. 543-557, 2012. 
Araujo, Ana Paula Correia de; Filartigas, Danilo Magno Espíndola; CARvalHo, Luciani Coimbra de. Bolivianos no Brasil: migração internacional pelo corredor fronteiriço Puertoquijarro (BO)/Corumbá (MS). Interações, v. 16, n. 1, p. 131-141, 2015.

BÄCKSTRÖM, Bárbara. Comportamentos de saúde e doença numa comunidade caboverdiana em Lisboa. Saúde e Sociedade, v. 20, n. 3, p. 758-772, 2011.

BARTLETT, Lesley; Rodríguez, Diana; Oliveira, Gabrielle. Migração e educação: perspectivas socioculturais. Educação e Pesquisa, v. 41, n. especial, p. 1153-1171, 2015.

BeShaROV, Douglas; LOPEZ, Mark; SIEGEL, Melissa. International conference news: trends in migration and migration policy. Journal of Policy Analysis and Management, v. 32, n. 3, p. 655-660, 2013.

BRANCANTE, Pedro Henrique; ReIS, Rossana Rocha. A "securitização da imigração": mapa do debate. Lua Nova: Revista de Cultura e Política, n. 77, p. 73-104, 2009.

BRITO, Fausto. A politização das migrações internacionais: direitos humanos e soberania nacional. Revista Brasileira de Estudos de População, v. 30, n. 1, p. 77-97, 2013.

BRzozowsKI, Jan. Migração internacional e desenvolvimento econômico. Estudos Avançados, v. 26, n. 75, p. 137-156, 2012.

CERNA, Lucie; $\mathrm{CHOU}$, Meng-Hsuan. The regional dimension in the global competition for talent: lessons from framing the European Scientific Visa and Blue Card. Journal of European Public Policy, v. 21, n. 1, p. 76-95, 2014.

CONDON, Meghan; FILINDRA, Alexandra; WICHOWSKY, Amber. Immigrant inclusion in the safety net: a framework for analysis and effects on educational attainment. Policy Studies Journal, v. 44, n. 4, p. 424-448, 2015.

CREEK, Heather; YODER, Stephen. With a little help from our feds: understanding state immigration enforcement policy adoption in American federalism. Policy Studies Journal, v. 40, n. 4, p. 674-697, 2012.

DA RoIT, Barbara; VAN BOCHOVE, Marianne. Migrant care work going Dutch? The emergence of a live-in migrant care market and the restructuring of the Dutch longterm care system. Social Policy \& Administration, vol. 51, n. 1, p. 76-94, 2015.

DA ROIT, Barbara; WEICHT, Bernhard. Migrant care work and care, migration and employment regimes: a fuzzy-set analysis. Journal of European Social Policy, v. 23, n. 5, p. 469-486, 2013.

DEEB-SOSSA, Natália et al. Experiencias de mujeres mexicanas migrantes indocumentadas en California, Estados Unidos, em su acceso a los servicios de salud sexual y reproductiva: estudio de caso. Cadernos de Saúde Pública, v. 29, n. 5, p. 981-991, 2013.

DEL-SOL-FLóREZ, Héctor. Una aproximación a la intervención educativa com menores migrantes no acompañados em España: paradojas de la inclusión social. Avaliação: Revista da Avaliação da Educação Superior, v. 17, n. 1, p. 137-153, 2012. 
FAgGian, Alessandra; Corcoran, Jonathan; RowE, Francisco. Evaluating the effects of Australian policy changes on human capital: the role of a graduate visa scheme. Environment and Planning C: Government and Policy, v. 34, n. 1, p. 151-170, 2016.

FosSATI, Flavia. The effect of integration and social democratic welfare states on immigrants' educational attainment: a multilevel estimate. Journal of European Social Policy, v. 21, n. 5, p. 391-412, 2011.

GeDDES, Andrew; JoRdAN, Andrew. Migration as adaptation? Exploring the scope for coordinating environmental and migration policies in the European Union. Environment and Planning C: Government and Policy, v. 30, n. 6, p. 1029-1044, 2012. Goldberg, Alejandro; SilveIRA, Cássio. Desigualdad social, condiciones de acceso a la salud pública y procesos de atención em inmigrantes bolivianos de Buenos Aires y São Paulo: una indagación comparativa. Saúde e Sociedade, v. 22, n. 2, p. 1-14, 2013.

INTERNATIONAL ORganization FOR MigRation (IOM). World Migration Report 2015. International Organization for Migration (IOM) Web Site. Disponível em: <http:// publications.iom.int/system/files/wmr2015_en.pdf>. Acesso em: 20/07/2016.

KISLEV, Elyakim. The effect of education policies on higher-education attainment of immigrants in Western Europe: a cross-classified multilevel analysis. Journal of European Social Policy, v. 26, n. 2, p. 183-199, 2016.

LEÃo, Augusto Veloso; DEMANT, Peter Robert. Mobilização política e integração de migrantes no Brasil: os casos Zulmira Cardoso e Brayan Capcha. Revista Brasileira de Ciências Sociais, v. 31, n. 91, p. 1-20, 2016.

LEWIS, Paul et al. Why do (some) city police departments enforce federal immigration law? Political, demographic, and organizational influences on local choices. Journal of Public Administration Research and Theory, v. 23, n. 1, p. 1-25, 2013.

LIEBERT, Saltanat; AMERINGER, Carl. The health care safety net and the Affordable Care Act: implications for Hispanic immigrants. Public Administration Review, v. 73, n. 6, p. 810-820, 2013.

MAdI, Maria Carolina; CASSANTI, Ana Carolina; SIlvelra, Cássio. Estudo das representações sociais sobre gestação em mulheres bolivianas no contexto da atenção básica em saúde na área central da cidade de São Paulo. Saúde e Sociedade, v. 18, n. 2, p. 67-71, 2009.

MARTES, Ana Cristina Braga; SOARES, Weber. Remessas de recursos dos imigrantes. Estudos Avançados, v. 20, n. 57, p. 41-54, 2006.

MARTIN, Susan. Environmental change and migration: legal and political frameworks. Environment and Planning C: Government and Policy, v. 30, n. 6, p. 1045-1060, 2012. MonogAN, James. The politics of immigrant policy in the 50 US States, 2005-2011. Journal of Public Policy, v. 33, n. 1, p. 35-64, 2013.

OliveIRA, Márcia Maria de. A mobilidade humana na tríplice fronteira: Peru, Brasil e Colômbia. Estudos Avançados, v. 20, n. 57, p. 183-196, 2006. 
PaIVA JúnIOR, Fernando Gomes de; Souza LeÃo, André Luiz Maranhão de; Mello, Sérgio Carvalho Benício de. Validade e confiabilidade na pesquisa qualitativa em Administração. Ciências da Administração, v. 13, n. 31, p. 190-209, 2011.

PATARRA, Neide Lopes. Migrações internacionais: teorias, políticas e movimentos sociais. Estudos Avançados, v. 20, n. 57, p. 7-24, 2006.

PATARRA, Neide Lopes; BAEnINGer, Rosana. Mobilidade espacial da população no Mercosul: metrópoles e fronteiras. Revista Brasileira de Ciências Sociais, v. 21, n. 60, p. 83-102, 2006.

RAMOS, Milena Yumi; VelHo, Lea. Formação de doutores no Brasil e no exterior: impactos na propensão a migrar. Educação \& Sociedade, v. 32, n. 117, p. 933-951, 2011.

REIS, Rossana Rocha. Migrações: casos norte-americano e francês. Estudos Avançados, v. 20, n. 57, p. 59-74, 2006.

RoDRIGUES, Francilene. Migração transfronteiriça na Venezuela. Estudos Avançados, v. 20, n. 57, p. 197-207, 2006.

SANTOS, Fabiane Vinente dos. A Inclusão dos migrantes internacionais nas políticas do sistema de saúde brasileiro: o caso dos haitianos no Amazonas. História, Ciências, Saúde - Manguinhos, v. 23, n. 2, p. 1-17, 2016.

SELBY, Jan; HofFMANN, Clemens. Water scarcity, conflict, and migration: a comparative analysis and reappraisal. Environment and Planning C: Government and Policy, v. 30, n. 6, p. 997-1014, 2012.

SHUTES, Isabel; CHIATTI, Carlos. Migrant labour and the marketisation of care for older people: the employment of migrant care workers by families and service providers. Journal of European Social Policy, v. 22, n. 4, p. 392-405, 2012.

SONG, Jiyeoun. Labour markets, care regimes and foreign care worker policies in East Asia. Social Policy \& Administration, v. 49, n. 3, p. 376-393, 2015.

ToPA, Joana; NEVES, Sofia; NogueIRA, Conceição. Imigração e saúde: a (in) acessibilidade das mulheres imigrantes aos cuidados de saúde. Saúde e Sociedade, v. 22, n. 2, p. 328-341, 2013.

TURNER, Robert; SHARRY, William. From progressive pioneer to nativist crackdown: the transformation of immigrant policy in Oklahoma. Politics \& Policy, v. 40, n. 6, p. 983-1018, 2012.

United Nations (UN). Population Facts. N²015/04. United Nations (UN) Web Site. Disponível em: <http://www.un.org/en/development/desa/population/ publications/pdf/popfacts/PopFacts_2015-4.pdf>. Acesso em: 20/07/2016.

VAN HOOREN, Franca. Varieties of migrant care work: comparing patterns of migrant labour in social care. Journal of European Social Policy, v. 22, n. 2, p. 133-147, 2012. VÉRAN, Jean-François; NOAL, Débora da; FAINSTAT, Tyler. Nem refugiados, nem migrantes: a chegada dos haitianos à cidade de Tabatinga (Amazonas). Dados, v. 57, n. 4, p. 1007-1041, 2014.

VILELA, Elaine Meire. Desigualdade e discriminação de imigrantes internacionais no mercado de trabalho brasileiro. Dados, v. 54, n. 1, p. 89-128, 2011. 
VILELA, Elaine Meire; SAMPAIO, Daniela Portela. Um olhar sobre as autorizações de permanência a estrangeiros no Brasil, entre 2005 e 2011. Revista Brasileira de Estudos de População, v. 32, n. 1, p. 25-48, 2015.

WARNER, Koko. Human migration and displacement in the context of adaptation to climate change: the Cancun adaptation framework and potential for future action. Environment and Planning C: Government and Policy, v. 30, n. 6, p. 1061-1077, 2012. WILLIAMS, Fiona; BRENNAN, Deborah. Care, markets and migration in a globalising world: introduction to the special issue. Journal of European Social Policy, v. 22, n. 4, p. 355-362, 2012.

WRIGHT, Chris. How do states implement liberal immigration policies? Control signals and skilled immigration reform in Australia. Governance, v. 27, n. 3, p. 397421, 2014.

WUNDERLICH, Daniel. The limits of external governance: implementing EU external migration policy, Journal of European Public Policy, v. 19, n. 9, p. 1414-1433, 2012.

\section{Frederico de Morais Andrade Coutinho}

Mestrado em andamento em Administração pela Universidade de Brasília (UnB). Atualmente é Especialista em Políticas Públicas e Gestão Governamental, atuando como Chefe de Gabinete da Secretaria Nacional de Promoção e Defesa dos Direitos Humanos da Secretaria de Direitos Humanos da Presidência da República (SDH/PR). Contato:fred_morais@yahoo.com.br

\section{Danilo Bijos}

Doutorado em andamento em Ciência Política pela Universidade de Brasília (UnB). Atualmente atua como economista concursado da Prefeitura de Unaí-MG. Contato: danilo.bijos@yahoo.com.br

\section{Henrique Marques Ribeiro}

Mestrado em andamento em Administração pela Universidade de Brasília (UnB). Atualmente exerce a função de analista legislativo do Senado Federal atuando no Instituto DataSenado. Contato: hrhenrique7@gmail.com 


\section{Anexo}

\section{Tabela 1 - Lista de periódicos selecionados}

\begin{tabular}{|c|c|}
\hline Título do periódico & Classificação \\
\hline BAR. Brazilian Administration Review & $A 2$ \\
\hline Cadernos EBAPE.BR (FGV) & $\mathrm{A} 2$ \\
\hline Cadernos de Saúde Pública (ENSP) & $\mathrm{A} 2$ \\
\hline Dados & $\mathrm{A} 2$ \\
\hline Organizações \& Sociedade & $\mathrm{A} 2$ \\
\hline RAC. Revista de Administração Contemporânea & A2 \\
\hline RAE. Revista de Administração de Empresas & A2 \\
\hline Revista Brasileira de Gestão de Negócios & $\mathrm{A} 2$ \\
\hline Revista Contabilidade \& Finanças & $\mathrm{A} 2$ \\
\hline Revista de Administração (FEA-USP) & $\mathrm{A} 2$ \\
\hline Revista de Administração Pública & $\mathrm{A} 2$ \\
\hline Ambiente e Sociedade (Campinas) & B1 \\
\hline BBR. Brazilian Business Review & B1 \\
\hline Bragantia (São Paulo, SP) & B1 \\
\hline Caderno CRH (UFBA. Impresso) & B1 \\
\hline Caderno Virtual de Turismo (UFRJ) & B1 \\
\hline Ciência e Saúde Coletiva & B1 \\
\hline Contabilidade Vista \& Revista & B1 \\
\hline Economia Aplicada & B1 \\
\hline Economia e Sociedade (UNICAMP) & B1 \\
\hline Enfoque: Reflexão Contábil & B1 \\
\hline Estudos Econômicos (São Paulo) & B1 \\
\hline Gestão \& Produção (UFSCAR) & B1 \\
\hline História, Ciências, Saúde-Manguinhos & B1 \\
\hline Nova Economia (UFMG) & B1 \\
\hline Novos Estudos CEBRAP & B1 \\
\hline
\end{tabular}




\begin{tabular}{|c|c|}
\hline Título do periódico & Classificação \\
\hline Perspectivas em Ciência da Informação & B1 \\
\hline Psicologia: Reflexão e Crítica (UFRGS) & B1 \\
\hline RAM. Revista de Administração Mackenzie & B1 \\
\hline REAd. Revista Eletrônica de Administração (Porto Alegre) & B1 \\
\hline Revista Brasileira de Ciências Sociais & B1 \\
\hline Revista Brasileira de Economia & B1 \\
\hline Revista Brasileira de Enfermagem & B1 \\
\hline Revista Brasileira de Estudos de População & B1 \\
\hline Revista Contemporânea de Contabilidade (UFSC) & B1 \\
\hline Revista Universo Contábil & B1 \\
\hline Revista da Escola de Enfermagem da USP & B1 \\
\hline Revista de Contabilidade e Organizações & B1 \\
\hline Revista de Economia Contemporânea & B1 \\
\hline Revista de Economia Política & B1 \\
\hline Revista de Economia e Sociologia Rural & B1 \\
\hline Revista de Gestão da Tecnologia e Sistemas de Informação & B1 \\
\hline Revista de Sociologia e Política (UFPR) & B1 \\
\hline Sociedade e Estado (UnB) & B1 \\
\hline Sociologias (UFRGS) & B1 \\
\hline Transinformação & B1 \\
\hline ActaScientiarum. Human and Social Sciences & B2 \\
\hline Administração Pública e Gestão Social & B2 \\
\hline Ambiente Construído & B2 \\
\hline Arkeos Perspectivas em Diálogo & B2 \\
\hline Avaliação (UNICAMP) & $\mathrm{B} 2$ \\
\hline Avaliação Psicológica & $\mathrm{B} 2$ \\
\hline Base (São Leopoldo) & B2 \\
\hline Base (UNISINOS) & B2 \\
\hline Cadernos Saúde Coletiva (UFRJ) & B2 \\
\hline
\end{tabular}




\begin{tabular}{|c|c|}
\hline Título do periódico & Classificação \\
\hline Cadernos de Linguagem e Sociedade & B2 \\
\hline CheckList (São Paulo) & B2 \\
\hline ConScientiae Saúde & B2 \\
\hline Desenvolvimento em Questão & B2 \\
\hline Eccos Revista Científica & B2 \\
\hline Economia (Brasília) & B2 \\
\hline Educação e Realidade & B2 \\
\hline Educar em Revista & B2 \\
\hline Educação \& Sociedade & B2 \\
\hline Educação e Pesquisa (USP) & B2 \\
\hline Ensaio (Fundação Cesgranrio) & B2 \\
\hline Ensaio: Pesquisa em Educação em Ciências & B2 \\
\hline Escola Anna Nery & B2 \\
\hline Estudos Avançados & B2 \\
\hline Estudos de Psicologia (UFRN) & B2 \\
\hline Faces: Revista de Administração (Belo Horizonte) & B2 \\
\hline Gestão \& Regionalidade & B2 \\
\hline História da Educação & B2 \\
\hline Informação \& Sociedade (UFPB) & B2 \\
\hline Interações (UCDB) & B2 \\
\hline Lua Nova & B2 \\
\hline Mercator (Fortaleza) & B2 \\
\hline Meta: Avaliação & B2 \\
\hline O Papel (São Paulo) & B2 \\
\hline Paidéia (USP. Ribeirão Preto) & B2 \\
\hline Produção (São Paulo) & B2 \\
\hline Psicologia e Sociedade & B2 \\
\hline Psicologia: Ciência e Profissão & B2 \\
\hline Psicologia: Teoria e Pesquisa (UnB) & B2 \\
\hline
\end{tabular}




\begin{tabular}{ll}
\hline Título do periódico & Classificação \\
\hline Psicologia: Teoria e Prática & B2 \\
\hline RAl : Revista de Administração e Inovação & B2 \\
\hline Revista Brasileira de Gestão e Desenvolvimento Regional & $\mathrm{B} 2$ \\
\hline Revista Brasileira de Pesquisa em Turismo & $\mathrm{B} 2$ \\
\hline Revista Direito GV & $\mathrm{B} 2$ \\
\hline Revista Mal-Estar e Subjetividade & $\mathrm{B} 2$ \\
\hline Revista Portuguesa e Brasileira de Gestão (Rio de Janeiro) & $\mathrm{B} 2$ \\
\hline Revista Turismo em Análise & $\mathrm{B} 2$ \\
\hline Revista de Administração da UFSM & $\mathrm{B} 2$ \\
\hline Revista de Antropologia & $\mathrm{B} 2$ \\
\hline Revista de Ciências da Administração (CAD/UFSC) & $\mathrm{B} 2$ \\
\hline Revista de Políticas Públicas (UFMA) & $\mathrm{B} 2$ \\
\hline Revista de Administração da Unimep & $\mathrm{B} 2$ \\
\hline Saúde em Debate & $\mathrm{B} 2$ \\
\hline Saúde e Sociedade (USP) & $\mathrm{B} 2$ \\
\hline Sociedade \& Natureza (UFU) & $\mathrm{B} 2$ \\
\hline Trabalho, Educação e Saúde & $\mathrm{B} 2$ \\
\hline Turismo: Visão e Ação & $\mathrm{B} 2$ \\
\hline Urbe. Revista Brasileira de Gestão Urbana & $\mathrm{B} 2$ \\
\hline
\end{tabular}

Fonte: Elaboração própria. 